\title{
Por uma história mais antropológica: indígenas na contemporaneidade
}

\author{
Cristiane de Assis Portela \\ Doutoranda em História Social (Universidade de Brasília) \\ Professora do Centro de Desenvolvimento Sustentável da Universidade de Brasília \\ Brasília, Brasil \\ ciseportela@yahoo.com.br
}

\begin{abstract}
Resumo
Proponho neste texto uma reflexão acerca da história indígena, percorrendo alguns momentos da historiografia brasileira em busca da percepção dos historiadores acerca do papel histórico desempenhado pelos indígenas em nossa história. Apresento um breve panorama do tratamento dado à história indígena desde o momento de profissionalização da disciplina História, trazendo como hipótese a ideia de que os indígenas foram in-visibilizados socialmente e silenciados discursivamente, ou seja, durante muito tempo suas vozes estiveram inaudíveis e suas histórias, invisíveis. Considero que a maneira pela qual foi tratada a história indígena gerou um círculo de estigmatização entre a marginalização historiográfica que lhes foi destinada e o apagamento social que foi reforçado em decorrência desta exclusão. Em busca de uma proposta de "história mais antropológica", recorro a leituras de João Pacheco de Oliveira Filho, Marshall Sahlins e Boaventura de Sousa Santos, considerando novas possibilidades teóricas para uma leitura das sociedades indígenas na contemporaneidade.
\end{abstract}

Palavras-chave: indígenas; historiografia; antropologia histórica; história indígena.

“Os índios vêm adquirindo o 'estranho' direito de continuar a ser índios, depois de quinhentos anos de integração forçada.” (Souza Filho, 2001, p. 258)

FRASE ACIMA CITADA sintetiza bem a contradição existente na
relação entre sociedades indígenas e a sociedade nacional na con-
temporaneidade. A história indígena no Brasil foi marcada pela impo-
sição de uma unidade nacional que excluía a diversidade e "lembrava",
sob diferentes formas de violência, que índios deveriam deixar de ser
índios. Na contemporaneidade, as formas de violência persistem, a des-
peito dos avanços jurídicos conquistados pelos movimentos indígenas
nas últimas décadas do século XX. Porém, no âmbito do imaginá-
rio nacional, há inúmeras ideias estereotipadas que foram consolida-
das historicamente e que hoje definem arbitrariamente "quem entra e
quem sai" no campo da identidade étnica. Enfim, permanece em nosso
imaginário um índio idealizado e anacrônico, visto por um espelho
que ainda reflete uma imagem colonial. Considerando esse contexto,
a proposta deste artigo é apresentar algumas ideias predominantes na
historiografia brasileira que trata o tema e, em seguida, propor aos his-
toriadores um diálogo com três pesquisadores que apontam caminhos
para produzir uma historiografia em "tempos de globalização".
Santos e Arriscado (2003, p. 25) lembram que existe uma ten-
são permanente entre a diferença e a igualdade que cada vez mais se
intensifica na contemporaneidade. Pensando essa relação, questionam:
"Como é possível, ao mesmo tempo, que seja reconhecida a diferença, 
tal como ela se constitui através da história, e exigir que os 'outros' nos olhem como iguais e reconheçam em nós os mesmos direitos de que são titulares?"

Quando se trata da relação entre índios e não índios, buscar esse equilíbrio entre igualdade e diferença é tarefa extremamente complexa, sobretudo por trazer em seu bojo a ruptura com visões já consagradas na história e tão reproduzidas pela historiografia brasileira. Nesse sentido, Leonardi (1996, p. 316) observa que "passar pela história do Brasil, entre árvores e esquecimentos, parece ser a sina do sertanejo e do índio".

Sina esta que se construiu de maneira contraditória e vacilante, a "esquizofrenia" a que se refere Rocha (2003, p. 39): "destruir o índio seria o mesmo que destruir a nós mesmos"! Daí que não tenha ocorrido uma clara política de extermínio dos índios, como aconteceu em outros países latino-americanos. No Brasil, os índios foram sendo apagados e invisibilizados, diluídos inicialmente entre árvores (a natureza, os animais) e, posteriormente, entre esquecimentos (os pobres, os despossuídos). Buscando compreender a forma com que esse processo ocorreu na historiografia, vamos percorrer alguns momentos dessas produções.

Concepções díspares povoaram a imaginação acerca do homem americano desde os primeiros momentos da colonização: enquanto o restante da Europa vê, aos olhos de Américo Vespúcio, algo belo e agradável, chegando até ao "bom selvagem", em Portugal, essa imagem não consegue difusão, assim como em sua colônia brasileira (considerando-se como exceção o período de exaltação indianista com o Romantismo do século XIX). A visão positiva sobre os índios se manteve para os europeus que desconheciam a América, da mesma forma que se mantém hoje para as populações brasileiras que desconhecem o "índio real".

Em 1838, com a criação do Instituto Histórico e Geográfico Brasileiro (IHGB), os indígenas aparecem como parte constitutiva da nação, porém, é preponderante a valorização da cultura lusitana (proposta de branqueamento populacional). A dissertação de Von Martius, intitulada "Como se deve escrever a história do Brasil", é texto fundador da história oficial do Brasil, estando nela contidos muitos elementos do olhar que a historiografia por muito tempo destinou aos povos indígenas. Nesta, a história do índio no Brasil tem relevância pelo caráter de exotismo e curiosidade que a permeia, devendo o historiador ser instigado pela explicação de como foram originadas essas "ruínas de povos".

Martius (1845, p. 92) contesta a ideia de que os indígenas representassem "um estado primitivo do homem", destituindo-lhes a história ao considerá-los como "resíduo de uma perdida história". Assim, primeiramente, deve-se considerá-los por suas características físicas e, a partir destas, seriam compreendidas as suas atividades "espirituais", tendo como documento mais significativo "a língua dos índios". Considerando o tupi como língua homogeneizadora dos povos do Brasil, Martius entende que "não podemos duvidar que todas as tribos, que nela fazem-se inteligíveis, pertençam a um único e grande povo, que sem dúvida possuiu a sua História própria, e que, de um estado florescente de civilização, decaiu para o atual estado de degradação e dissolução" (Martius,1845, p. 92).

Buscando compreender esse estado de degradação, ele indica que as investigações historiográficas deveriam centrar-se na língua e na mitologia, havendo a necessidade de analisar os rituais como representativos da degeneração e as relações sociais e jurídicas como exemplo da dissolução desses grupos. A menção aos indígenas se encerra com uma referência aos estudos de Lafitau, jesuíta que, no século XVIII, se insere no debate que tenta estabelecer um lugar para o "selvagem" no curso da humanidade, propondo um quadro comparativo destes com os "bárbaros" da Antiguidade, a fim de que se identifique uma origem que seria comum a ambos. Aponta também a necessidade de buscas arqueológicas na esperança de que se encontrem vestígios de civilizações comparáveis a outros povos americanos (incas, astecas e maias).

A proposta de Martius (1845) é desenvolvida por Varnhagen (1978), que consagra a ideia de que para os índios não há história, apenas etnografia. Vale ressaltar que ele traz em sua obra constantes defesas das práticas coercitivas aos indígenas. Em suas palavras: "Tem-se clamado injustamente contra as tendências dos primitivos colonos de levarem a ferro e fogo os bárbaros da terra" (1978, p. 210). Varnhagen justifica ainda que o emprego da força para a "civilização" dos índios era o único meio possível para empreender a colonização.

Assim, permanece no século XIX e no início do século XX a tese de extinção dos povos indígenas, sob influência da teoria norte-americana de aculturação. Como consequência, é adotada uma política indigenista de descaracterização cultural e de extermínio físico, com a naturalização da ação civilizatória através de uma integração que se pressupunha inevitável:

\begin{abstract}
Mesmo nas fases mais esclarecidas da "proteção" oficial, os órgãos indigenistas trabalhavam no sentido de amenizar o impacto do processo "civilizatório", considerado um fato inevitável que, dia mais, dia menos, levaria à completa integração dos índios à nação brasileira. (Monteiro, 1995, p. 222-223)
\end{abstract}

Esse autor evidencia ainda que a "tese da extinção" é um traço comum que une as perspectivas de diferentes pesquisadores, aproximando Darcy Ribeiro (1970) de Martius (1845) e de Varnhagen, e mesmo dos viajantes do século XIX: "se há um traço comum entre estes observadores e pensadores, tão dispersos no tempo, é o pessimismo com que encaravam o futuro dos povos nativos" (Monteiro, 1995, p. 222).

$\mathrm{Na}$ mesma perspectiva que busca naturalizar a violência aos índios, Taunay (1979), em suas observa- 
ções acerca das bandeiras paulistas, através de elogios ufanistas aos feitos bandeirantes, considera que as violências empreendidas contra os índios eram "coisas da época", além disso, pondera que os portugueses não poderiam ser condenados por tais feitos, já que era prática comum também aos espanhóis e outros europeus. Aliás, as práticas violentas da colonização espanhola foram apresentadas como contraponto necessário para a afirmação de que houve uma colonização branda no Brasil, ideia por muito tempo persistente, já que não existem relatos escritos por indígenas brasileiros que comprovem tais agressões, conforme os existentes entre astecas e maias-toltecas.

Ideias como as de Varnhagen e Taunay são transplantadas para os livros didáticos, reproduzindo durante a maior parte da história do Brasil noções equivocadas, às quais Leonardi (1996) ironiza, chamando-as de "filosofias dos danos inevitáveis e necessários" e "filosofias da morte construtiva". No sentido dessas filosofias, Oliveira Viana (1920), seguindo os preceitos biológico-raciais de Goubineau, faz um elogio à guerra contra índios, negros e mestiços desocupados, considerando estes como inferiores física e intelectualmente.

Há de se observar que as impressões de Taunay e de Viana se apresentaram num momento em que a antropologia já se estruturara como ciência e que diversos trabalhos já retratavam a situação dos índios no Brasil. Além disso, devemos lembrar que temos Capistrano de Abreu (1976) como uma das vozes dissonantes na historiografia do início do século XX. Abreu foi duramente criticado por não se dedicar exclusivamente à construção de uma "grande história brasileira", da qual os índios deveriam estar excluídos. A contragosto da corrente intelectual da época, realizou trabalhos etnográficos entre os Bakairi e Kaxinawá, apesar de não ter avançado em direção à elaboração de uma história indígena.

Gilberto Freyre, na década de 1930, traz, com Casa-grande e senzala, uma abordagem inovadora para a época, ao inserir conjuntamente os três elementos de nacionalidade - branco, índio e negro -, incorporando pela primeira vez na historiografia as indicações de Martius em "Como se deve escrever a história do Brasil". Sem se deter nas críticas quanto a sua tão criticada "tese de democracia racial", basta ressaltar que Freyre utiliza designações como "raça atrasada" ou "bandos de crianças grandes" para se referir aos indígenas em sua tríade nacional. Em outro texto, ao se referir à exploração dos "sertões" do Brasil, utiliza o termo "autocolonização" para definir a ocupação por brasileiros dos imensos "espaços vazios" do interior. Essa noção de esvaziamento dos sertões, tão cara aos viajantes do século XIX, é utilizada por ele até o fim do século XX, por exemplo, quando argumenta em favor da construção da Transamazônica e do abrasileiramento dos índios (ver Freyre, 1987).
Leonardi (1996, p. 38) avalia que, "depois das tolices da historiografia tradicional a respeito dos índios, tivemos o silêncio da historiografia posterior". De fato, Prado Júnior (1977, p. 79), atento à formação de uma sociedade moderna, demonstra que o índio foi "o problema mais complexo que a colonização teve de enfrentar", neste sentido, ele considera que, sem uma ação agressiva por parte do governo, muitas capitanias não teriam se constituído (o que não deixa de ser uma verdade!), e complementa sua análise dizendo que, após essas atitudes, o índio deixou de ser um "problema".

Entende-se que o fato de "deixar de ser um problema" fez com que os indígenas "desaparecessem" completamente da história do Brasil moderno. Aí se encontra o equívoco! Sintomaticamente, o índio não aparece mais na obra de Prado Jr. nem dos historiadores contemporâneos a ele. Categoria do passado, diluídos num projeto de modernidade, restaria à antropologia atribuir-lhes um papel. Vainfas explica que índios e negros eram "povos que Caio Prado desqualifica um pouco por causa da escravidão, outro tanto pela inferioridade cultural e racial que lhes atribui de antemão" (1999, p. 7). Nesse sentido, o pensamento de Caio Prado Jr. parece não se distanciar muito dos clássicos da historiografia brasileira. A observação de Leonardi (1996, p. 176) reforça essa análise:

A impossibilidade de se atribuir aos povos indígenas do Brasil uma missão ou papel, na história econômica contemporânea, deve ter sido a principal responsável por esse desinteresse ou esquecimento. Com isso, o final do Império e o período republicano costumam ser estudados basicamente em torno das figuras centrais da burguesia cafeeira, do campesinato e do proletariado industrial, como se a questão indígena nos séculos XIX e XX já fosse anacrônica. $\mathrm{Ou}$ área exclusiva da antropologia.

Ainda segundo Leonardi (1996, p. 176), essa lacuna historiográfica é decorrente do predomínio de ideologias do progresso, que tiveram enorme alcance nas produções brasileiras, tanto em sua vertente iluminista quanto positivista e marxista. Considerando que após a superação da historiografia tradicional de forte tendência hankeana, o marxismo é o aporte teórico utilizado para a historiografia moderna brasileira, Leonardi (1996, p. 162) levanta a hipótese de que o abandono da temática indígena na história social do Brasil "deve-se, em parte, à inconsistência das teses filosóficas de Marx a respeito da questão”. Assim, considera que,

Depois dos preconceitos tradicionais a respeito do índio, muito comuns na historiografia brasileira do século XIX e início do século XX, foi por não terem encontrado estímulo teórico suficiente no marxismo que alguns historiadores brasileiros deixaram de lado 
esse tema, como se as questões que o envolvem fossem de interesse exclusivo da etnografia. É como se a industrialização e a Modernidade tivessem feito desaparecer, do Brasil, o seu imenso sertão. (Leonardi, 1996, p. 162)

Não cabe aqui avaliar a interpretação que Leonardi (1996) faz das produções marxistas, sendo significativo, para nossa análise, apenas considerar que, na segunda metade do século XX, os trabalhos historiográficos brasileiros foram predominantemente de cunho marxista e as análises, de fato, se esquivavam da temática indígena. ${ }^{1}$ Evitando abordá-la ou tratando o tema de maneira irrelevante, consideraram os indígenas como empecilhos ao progresso, "retirando-os" da história ainda no período colonial.

É importante observar que, no Brasil, outras perspectivas de leitura da história coexistiam com o marxismo nesse período, em especial a linha francesa dos Annales (trazida ao Brasil por Braudel). Além desta, persistiam as visões tradicionais do historicismo rankeano e do positivismo comteano. Porém, a perspectiva marxista foi hegemônica no Brasil até a década de 1990, daí a relevância da observação de que o "apagamento" dos indígenas na história brasileira deve-se parcialmente à ausência de espaços nessa linha de análise.

Em um contexto internacional, desde os anos 60 e 70, "os silêncios de Marx" começaram a ser explorados na Inglaterra por Edward Thompson e Raymond Williams. Enquanto isso, na França, processava-se um repensar dos pressupostos dos Annales, inserindo-se a análise das mentalidades, em um movimento de busca por novos referenciais, o que Le Goff (2001) denominou como "Nova História". O que se apresenta é um contexto de inconformismo com a situação da historiografia, acusada de um vazio teórico. Pesavento (2003) entende que esse fenômeno é resultado de uma crise paradigmática pela qual passavam as ciências humanas e observa que há um repensar da historiografia em vários países além da Inglaterra e da França, como a Itália, os Estados Unidos, a Alemanha, Portugal e a Argentina.

Essa "crise de paradigmas" chega ao Brasil em meados da década de 1980, quando o país passava por um processo de redemocratização política, momento em que predominavam as leituras marxistas de Caio Prado Jr. e Nelson Werneck Sodré, entendidas como as mais eficientes para a análise do contexto ditatorial. A partir da década de 1990, sob forte crítica ao marxismo e às concepções da linha francesa dos Annales, uma nova tendência passa a predominar no Brasil, a História Cultural, sendo significativo que a maior parte da produção historiográfica atual se faça sob essa perspectiva (ver Pesavento, 2003).
Há de se observar que não é a abordagem cultural da história que "nasce" nesse momento. Mundialmente, vários trabalhos já discutiam desde o século XIX temas relacionados à cultura e, além disso, uma perspectiva culturalista já havia sido apresentada no Brasil por Gilberto Freyre e Sérgio Buarque de Holanda desde a década de 1930. O que se propõe, a partir desse momento, é uma outra forma de construção da história, através de novas possibilidades de temas, metodologias e fontes documentais, em uma aproximação intensa com ciências afins.

Diversas noções comportam aquilo que chamamos de História Cultural. Certo é que uma aproximação cada vez mais intensa com a antropologia atribui um significado claro à História Cultural, daí a observação de Darnton (1986, p. XIII, XIV) de que esta linha de análise é "história de tendência etnográfica" e, nesse sentido, "o historiador etnográfico estuda a maneira como as pessoas comuns entendem o mundo. Tenta descobrir sua cosmologia, mostrar como organizavam a realidade em suas mentes e a expressavam em seu comportamento". Darnton (1986) observa que a história é uma ciência interpretativa a qual cabe "decifrar os significados". Em suas palavras:

O método antropológico da História tem rigor próprio [. . . Começa com a premissa de que a expressão individual ocorre dentro de um idioma geral, de que aprendemos a classificar as sensações e a entender as coisas pensando dentro de uma estrutura fornecida por nossa cultura. Ao historiador, portanto, deveria ser possível descobrir a dimensão social do pensamento e extrair a significação de documentos, passando do texto ao contexto e voltando ao primeiro, até abrir caminho através de um universo mental estranho. (Darnton, 1986, p. XVII)

É no contexto de uma história social que avança para uma leitura cultural que a história indígena adquire uma nova feição, passando a ser incorporada como objeto de estudo da disciplina histórica. Se considerarmos que, no Brasil, desde a criação do Instituto Histórico e Geográfico Brasileiro (IHGB), no século XIX, até meados do século XX predominou uma perspectiva tradicional que considerava as sociedades indígenas como inferiores e destituídas de história, e que a superação dessa tendência só veio com a interpretação marxista a partir da década de 1960 (na qual o "apagamento" da história indígena foi tão grande quanto), constata-se, não sem admiração, a ausência historiográfica do indígena em praticamente toda a história do Brasil.

Para Moreira (2001), a invisibilidade historiográfica dos indígenas é decorrente de uma pequena 
visibilidade destes no ambiente social, sendo constituído, a partir de então, um "círculo vicioso" entre a marginalização social e a invisibilidade histórica. Invertendo os termos utilizados pela autora, considero a existência de um processo histórico de invisibilização social e marginalização historiográfica dos indígenas. Isso porque é predominante ainda hoje a ideia de que não existem mais índios "de verdade" (por isso, são invisíveis socialmente) e, além disso, a historiografia (ainda com poucas exceções) desconsiderou a existência destes como agentes históricos plenos, sendo geralmente referidos como parte de um passado distante, quando foram (mais uma vez) empecilhos ao progresso, daí a ideia de marginalidade historiográfica.

Demonstrada a pequena visibilidade atribuída à temática indígena na historiografia, proponho que consideremos a contribuição de três pesquisadores que, por meio de seus trabalhos, trazem algumas análises que considero esclarecedoras para a produção histórica sobre indígenas na contemporaneidade. São eles o antropólogo norte-americano Marshall Sahlins, o cientista social brasileiro João Pacheco de Oliveira Filho e o sociólogo português Boaventura de Sousa Santos.

O primeiro deles, Marshall Sahlins, propõe um diálogo renovado entre a história e a antropologia, retomando as obras de Braudel e de Levi-Strauss a fim de colocar as duas ciências em diálogo. Sahlins (1990) entende que a estrutura é composta por categorias culturais concebidas como uma rede, ou seja, um sistema de diferenças ou um conjunto de categorias. Sua proposta é repensar, em termos dialéticos, estrutura e evento/estrutura e história, o que o faz concluir que, enquanto a história transforma essas "redes culturais"-estrutura, a própria história é reordenada no mesmo processo. Assim:

\begin{abstract}
A história é ordenada culturalmente de diferentes modos nas diversas sociedades, de acordo com o esquema de significação das coisas, sendo que o contrário também é verdadeiro: esquemas culturais são ordenados historicamente porque, em maior ou menor grau, são reavaliados quando realizados na prática. (Sahlins, 1990, p. 7)
\end{abstract}

Para Sahlins (1990, p. 180), “a cultura funciona como uma síntese de estabilidade e mudança, de passado e presente, de diacronia e sincronia", assim, "toda mudança prática também é uma reprodução cultural”. Considero esta definição apropriada à análise histórica de diversas comunidades indígenas no Brasil, por focalizar uma perspectiva dinâmica que não compartimentaliza temporalidades (passado e presente como momentos destoantes). Esse poder de transformação que os "signos em ação" (termo utilizado por Sahlins) têm são decorrentes do que ele denomina como "estrutura da conjuntura". Esta consiste no conjunto de relações históricas que, a um só tempo, podem reproduzir categorias culturais tradicionais ou atribuirlhes novos valores a partir do que exige o contexto pragmático. Com base na mobilidade da "estrutura da conjuntura", Sahlins (1990) conclui que culturas diferentes apresentam historicidades diferentes. Considero de relevância fundamental o tratamento dado por esse autor ao termo cultura, pensando-o por meio do diálogo entre história e antropologia.

$\mathrm{Na}$ mesma perspectiva de uma "antropologia histórica", é essencial destacar a contribuição dos trabalhos de João Pacheco de Oliveira Filho (1998, 1999), no que tange à metodologia de trabalho aplicada à história indígena na contemporaneidade. Tendo como objeto de estudo as situações indígenas do Nordeste brasileiro e os processos de etnogênese delas decorrentes, sua obra fornece subsídios para pensar as sociedades indígenas em um contexto bem mais amplo. Contrastando a situação dos povos indígenas da Amazônia com os do Nordeste, Oliveira Filho (1998) observa que, enquanto em relação aos primeiros são enfatizadas as dimensões geopolíticas e ecológicas, no caso do Nordeste evidenciam-se apenas as políticas assistencialistas e a questão fundiária.

Daí que estes últimos tenham sido por muito tempo tema "desinteressante" para os pesquisadores, o que Oliveira Filho (1998) explica pelo fato de terem sido avaliados como "uma etnologia menor". Consideradas as devidas proporções, em muitos aspectos se assemelha a situação de índios em contextos urbanos (cidades que cresceram em torno de aldeias) com a dos indígenas do Nordeste. Um exemplo é o tratamento dado aos Karajá de Aruanã, em Goiás, vistos como "remanescentes" da etnia, sendo descritos apenas pelo que um dia foram, desconsiderando-se suas características culturais na atualidade (acerca desta situação histórica ver Portela, 2006). A essa tendência, Oliveira Filho (1998) define, referindo-se às etnias do Nordeste, como "etnologia das perdas".

Contrário a essa "etnologia das perdas", Oliveira Filho (1998, p. 54) propõe uma outra maneira de conceber a etnogênese. Para ele, importa perceber a existência de "um fato histórico - a presença colonial - que instaura uma nova relação da sociedade com o território, deflagrando transformações em múltiplos níveis de sua existência sociocultural". Nesse sentido, a ideia de "territorialização"2 deve ser pensada com es-

2 Por territorialização, o autor entende "um processo de reorganização social que implica: 1) a criação de uma nova unidade sociocultural mediante o estabelecimento de uma identidade étnica diferenciadora; 2) a constituição de mecanismos políticos especializados; 3 ) a redefinição do controle social sobre os recursos ambientais; 4) a reelaboração da cultura e da relação com o passado" (Oliveira Filho, 1998, p. 55). Ele destaca também que a noção de territorialização tem a mesma função que a definição de "situação colonial" trabalhada por Balandier e reelaborada por Cardoso de Oliveira. 
pecial atenção por estar diretamente relacionada com a definição de etnicidade esboçada em seu trabalho:

A etnicidade supõe, necessariamente, uma trajetória (que é histórica e determinada por muitos fatores) e uma origem (que é uma experiência primária, individual, mas que também está traduzida em saberes e narrativas aos quais vem a se acoplar). O que seria próprio das identidades étnicas é que nelas a atualização histórica não anula o sentimento de referência à origem, mas até mesmo o reforça. É da resolução simbólica e coletiva dessa contradição que decorre a força política e emocional da etnicidade. (Oliveira Filho, 1998, p. 64)

Fazendo uso da expressão poética "viagem $d a$ volta", Oliveira Filho (1998) simboliza de maneira salutar a contradição a ser resolvida pelos grupos étnicos em suas definições identitárias. Segundo ele, somente através da elaboração de utopias (sejam elas religiosas, morais ou políticas), permite-se "a superação da contradição entre os objetivos históricos e o sentimento de lealdade às origens, transformando a identidade étnica em uma prática social efetiva" (Oliveira Filho, 1998, p. 66).

A partir da noção de "situação histórica", Oliveira Filho (1998) apresenta quatro recomendações metodológicas a serem observadas pelo pesquisador, a fim de constituir uma "antropologia histórica" que possibilite um olhar diferenciado daquela "etnologia das perdas" predominante durante a maior parte da história dos povos indígenas considerados "misturados":

1) os povos indígenas hoje estão tão distantes de culturas neolíticas pré-colombianas quanto os brasileiros atuais da sociedade portuguesa do século XV, ainda que possam existir, nos dois casos, pontos de continuidade [...]; 2) não é possível descrever os fatos e acontecimentos dentro de uma temporalidade única e homogeneizadora - a longa duração [...]; 3) seria extremamente empobrecedor despojar as intervenções verbais dos nativos de uma dimensão crítica e explicativa que esteja associada a "comunidades de argumentação" [...] e 4) as culturas não são coextensivas às sociedades nacionais, nem ao grupo étnicos, alguns autores sugerem abandonar imagens arquitetônicas de sistemas fechados e passar a trabalhar com processos de circulação de significados. (Oliveira Filho, 1998, p. 68-69)

Em conformidade com as indicações de Oliveira Filho (1998), considero interessante incorporar (na medida do possível) suas observações metodológicas, entrecruzando olhares acerca de uma mesma situação histórica e atentando para alguns aspectos trazidos em sua definição: a dinamicidade cultural das sociedades, a construção de uma história constitutiva que abarca diferentes temporalidades, a importância de resgatar diferentes pontos de vista acerca da mesma situação e a percepção da circularidade de significados entre índios e não índios. Por meio dessas considerações, é possível que analisemos a história indígena em toda sua complexidade, buscando um redimensionamento do olhar do historiador acerca dos indígenas, ao percebê-los como agentes históricos fundamentais em nossa história social.

Ao dialogar com autores que têm trabalhado com as reelaborações culturais de sociedades indígenas no Brasil (especialmente com os excelentes trabalhos produzidos sobre o Nordeste indígena), instigou-me a percepção de que esses "movimentos de ressignificação étnica" estão incluídos em um contexto histórico muito mais amplo, um contexto em que identidades são confrontadas e sobrepostas e que, longe de representarem retornos nostálgicos ao passado, são fenômenos plenamente representativos da contemporaneidade. Diante desta observação, vale se deter um pouquinho mais na leitura de Sahlins, através de um outro texto de sua autoria, no qual ele considera que "a sobrevivência cultural no mundo moderno consiste na tentativa dos povos de se apropriarem desse mundo em seus próprios termos" (Sahlins, 1997, p. 123).

Para argumentar sobre o quanto um conceito consciente de cultura é uma arma poderosa para os indígenas na contemporaneidade, Sahlins (1997) utiliza Turner (1987) e sua definição de que a cultura "deve ser entendida, essencialmente, como o meio pelo qual um povo define e produz a si mesmo enquanto entidade social em relação à sua situação histórica em transformação" (Turner, 1987 apud Sahlins, 1997, p. 122). Tomando como exemplo a experiência de Terence Turner entre os Kayapó Gorotide, Sahlins (1997) demonstra a capacidade indígena de reelaborar culturalmente suas histórias, mesmo a partir de situações que lhes são desfavoráveis. Diz ainda que esta é só uma dentre as diversas expressões locais de um fenômeno mundial. Em suas palavras:

Esse tipo de autoconsciência cultural, conjugado à exigência política de um espaço indígena dentro da sociedade mais ampla, é um fenômeno mundial característico do fim do século XX. As antigas vítimas do colonialismo e do imperialismo descobriram sua "cultura". Por muito e muito tempo os seres humanos falaram cultura sem falar em cultura — não era preciso sabê-lo, pois bastava vivê-la. E eis que de repente a cultura se tornou um valor objetivado, e também o objeto de uma guerra de vida ou morte [...] A "cultura" - a palavra mesma ou algum equivalente local — está na boca do povo, sobretudo no contexto das forças nacionais e globais que ameaçam os modos tradicionais de existência do(s) povo(s). (Sahlins, 1997, p. 127)

Nesse mesmo texto, o próprio Sahlins (1997, p. 9) alerta para o risco de se ignorar "a agonia de povos inteiros, causada pela doença, violência, escravidão, expulsão do território tradicional e outras misérias 
que a 'civilização' ocidental disseminou pelo planeta". No entanto, devemos estar vigilantes para a sedução de uma perspectiva demasiadamente otimista quanto à capacidade dos povos indígenas de reelaborarem suas histórias a partir de uma lógica cultural própria. O risco que se apresenta é o de abandonar o fato de uma sujeição histórica que se processou por meio de uma relação desigual de forças. Neste trabalho, a tentativa de perceber os indígenas como agentes históricos plenos fez-se de maneira a não desvincular essa percepção das relações díspares de poder que claramente constituem todos os momentos dessa história.

Feita esta ressalva, vale destacar na citação acima a observação de Sahlins quanto à importância da apropriação do termo "cultura" não só pelos povos indígenas, mas por diversas formas de coletividades contemporâneas. De fato, essa "objetivação" da cultura constrói discursos que alteram a percepção que os outros têm sobre o grupo, assim como modifica a autoidentificação da comunidade com um reforço do sentimento de copertencimento. Ainda segundo Sahlins (1997), mesmo que os meios utilizados sejam modernos, os fins continuam a ser indígenas.

Os fenômenos recentes de "ressurgimentos" étnicos dão o ar de "retorno à tradição étnica", mas podem ser pensados de maneira diversa e bem mais frutífera, percebendo-os como parte dos "grandes empreendimentos identitários" do mundo contemporâneo. Estes parecem ser apenas simulacros que ocultam a existência de um "grande projeto identitário" plenamente inserido no contexto destes "tempos de globalização" e que se fazem sob o manto de um simples fenômeno cultural local. Conforme Agier (2001, p. 10-11):

As evoluções sociais e políticas das últimas décadas impõem um objeto empírico relativamente novo para a antropologia: o dos grandes empreendimentos identitários, que tendem a substituir as antigas "tribos", as aldeias "perdidas" e outras etnias "em via de desaparecimento" da etnologia clássica. Assistimos então a atitudes que se dão o ar de retornos ("retorno à etnia") ou de recolhimento ("recolhimento sobre si", "recolhimento identitário", busca de "raízes") quando, ao descodificar [sic] os processos e resultados de sua busca, descobrimos antes inovações, invenções, mestiçagens e uma grande abertura para o mundo presente.

Nos últimos anos, muito se produziu academicamente sobre "globalização" e mais ainda se comentou cotidianamente. Talvez depois da difusão do termo cultura, "globalização" seja uma das expressões sobre as quais mais se falou. Ganhando novas conotações "na boca do povo" (para utilizar uma expressão de Sahlins, 1997), esse termo foi reproduzido sem que se compreendesse exatamente a definição original. De maneira vaga, a ideia difundida foi a de que tudo aquilo que não "vemos", mas que tem poder e força que não podem ser combatidos, e que um dia inevitavelmente vai fazer sucumbir tudo aquilo que é "menor", é efeito da globalização. Quanto ao termo, Santos (2002, p. 49) observa que, "aparentemente transparente e sem complexidade, a ideia de globalização obscurece mais do que esclarece o que se passa no mundo".

Numa postura crítica à tendência de considerar a globalização como fenômeno monolítico e linear, e de abordá-la somente pelo viés econômico, Santos (2002) destaca a necessidade de perceber os efeitos da globalização também nos aspectos sociais, políticos e culturais. A despeito de uma crença na força inexorável da globalização, este sociólogo nos faz notar que a especificidade da globalização nas três últimas décadas é que, ao invés de reter como características a homogeneização e a uniformização, "as globalizações" parecem ter combinado a estas características "o particularismo, a diversidade local, a identidade étnica e o regresso ao comunitarismo" (Santos, 2002, p. 26). Neste sentido,

Os poderosos e envolventes processos de difusão e imposição de culturas, imperialisticamente definidas como universais, têm sido confrontados, em todo o sistema mundial, por múltiplos e engenhosos processos de resistência, identificação e indigenização culturais. (Santos, 2002, p. 47)

Santos (2002) demonstra a impossibilidade de conceber a globalização como fenômeno unitário, já que ela se constitui como campo de conflitos entre interesses hegemônicos e subalternos (sendo que os primeiros é que induzem à ideia tão difundida de um fenômeno avassalador). Composta por uma diversidade de processos que por vezes são contraditórios, só é possível falar de "globalizações", por ser um termo plural. Ao contexto contemporâneo, que Santos denomina de "sistema mundial em transição", cabe a seguinte definição de globalização:

Conjuntos de relações sociais que se traduzem na intensificação das interações transnacionais, sejam elas práticas interestatais, práticas capitalistas globais ou práticas sociais e culturais transnacionais. A desigualdade de poder no interior dessas relações (as trocas desiguais) afirmase pelo modo como as entidades ou fenômenos dominantes se desvinculam dos seus âmbitos ou espaços e ritmos locais de origem, e, correspondentemente, pelo modo como as entidades ou fenômenos dominados, depois de desintegrados e desestruturados, são revinculados aos seus âmbitos, espaços e ritmos locais de origem. Neste duplo processo, quer as entidades ou fenômenos dominantes (globalizados), quer os dominados (localizados) sofrem transformações internas. (Santos, 2002, p. 85 , grifos meus)

Conforme a citação acima, dentre as diversas "constelações de práticas" que caracterizam os pro- 
cessos de globalização contemporânea, três domínios são apontados como centrais: 1) práticas interestatais; 2) práticas capitalistas globais, e 3) práticas sociais e culturais transnacionais. Para a análise dos fenômenos identitários que caracterizam na contemporaneidade as sociedades indígenas brasileiras, o terceiro processo por ele apresentado tem grande relevância, já que:

No domínio das práticas sociais e culturais transnacionais, as trocas desiguais dizem respeito a recursos não mercantis cuja transnacionalidade assenta na diferença local, tais como etnias, identidades, culturas, tradições, sentimentos de pertença, imaginários, rituais, literatura escrita ou oral. São incontáveis os grupos sociais envolvidos nestas trocas desiguais e as suas lutas travam-se em torno do reconhecimento da apropriação ou da valorização não mercantil desses recursos, ou seja, em torno da igualdade na diferença e da diferença na igualdade. (Santos, 2002, p. 60, grifo meu)

Já comentei na introdução a este texto acerca da complexidade que marca a relação entre igualdade e diferença. Percebidos principalmente nos âmbitos locais, os embates decorrentes da conquista da igualdade e do reconhecimento da diferença indicam o alcance das "trocas desiguais" no contexto contemporâneo mais cotidiano. Lembrando que a globalização é sempre a "globalização bem-sucedida de localismos", Santos (2002) ressalta o quanto a dicotomia local/global adquiriu relevância no "sistema mundial em transição", estando presente tanto no discurso científico quanto no político.

A peculiaridade da análise de Santos (2002) reside em diferenciar duas formas de globalização: a hegemônica e a contra-hegemônica. Uma leitura monolítica da globalização restringe a percepção desse fenômeno apenas às características da primeira, daí decorre a ideia de um fenômeno avassalador. Partindo da definição dessas duas formas de globalização, e entendendo-as como campos em constante conflito, Santos (2002) destaca que a resistência mais eficaz contra a vertente hegemônica reside nas economias e culturas locais ${ }^{3}$ comunitárias e autossustentáveis.

Assim, em economias e culturas "cada vez mais desterritorializadas, a resposta contra os seus malefícios não pode deixar de ser a reterritorialização, a redescoberta do sentido do lugar e da comunidade, o que implica a redescoberta ou a invenção de atividades produtivas" (Santos, 2002, p. 72). Apesar de não ser uma estratégia que colida diretamente com a expansão da globalização hegemônica, nesse tipo de resposta contra-hegemônica, uma transformação pode vir através da construção de um "multiculturalismo emancipatório", 4 ou seja, é possível alterar as formas de partilha entre culturas distintas, orientando-as pela ideia de que "temos o direito de ser iguais quando a diferença nos inferioriza e a ser diferentes quando a igualdade nos descaracteriza" (Santos, 2002, p. 75).

A fim de melhor localizar as estratégias identitárias utilizadas pelas sociedades indígenas brasileiras, vale distinguir "graus de intensidade da globalização", diferenciando-os entre fenômenos dominantes (globalização de alta intensidade) e fenômenos dominados (globalização de baixa intensidade):

Enquanto as transformações dos fenômenos dominantes são expansivas, visam ampliar âmbitos, espaços e ritmos, as transformações dos fenômenos dominados são retrativas, desintegradoras e desestruturantes; os seus âmbitos e ritmos, que eram locais por razões endógenas e raramente se autorrepresentavam como locais, são relocalizados por razões exógenas e passam a autorrepresentar-se como locais. (Santos, 2002, p. 86)

Ao observar a existência de razões exógenas e razões endógenas, Santos nos faz perceber que a identidade se constrói sempre por meio do contraste com outras identidades, adquirindo importância, exatamente por isso, o fato de se questionar externamente o sentimento de pertencimento interno ao grupo. Nesse sentido, fundamental é saber quem pergunta pela identidade. Em resposta a essa pergunta é que a comunidade afirma sua distintividade, reforçando sua existência local e "objetivando" sua cultura como traço que a diferencia e que pela mesma razão exige, paradoxalmente, a igualdade de direitos.

Inovador na leitura de Santos (2002) é perceber - ao contrário daqueles que viam na globalização um acontecimento sem precedentes pela forma e pela intensidade - a "existência de duas faces da mesma moeda". Essas duas faces são: a) a desterritorialização, a desvinculação e a transformação expansiva, e b) a reterritorialização, a revinculação local e a transformação desintegradora e retrativa. Aparentemente vistos como fenômenos opostos, designam para Santos (2002, p. 86) diferentes intensidades de globalização: fenômenos mais lentos e difusos são, com suas características de relocalização e reterritorialização, partes da globalização contra-hegemônica e podem ser vistos, conforme afirmou Agier (2001), como fenômenos plenamente representativos da contemporaneidade.

3 Por "localização", Boaventura Santos entende "o conjunto de iniciativas que visam criar ou manter espaços de sociabilidade de pequena escala, comunitários, assentes em relações face a face, orientados para a autossustentabilidade e regidos por lógicas cooperativas e participativas [...]. Muitas destas iniciativas ou propostas se assentam na ideia de que a cultura, a comunidade e a economia estão incorporadas e enraizadas em lugares geográficos concretos que exigem observação e proteção constantes" (Santos, 2002, p. 72).

4 Acerca deste "multiculturalismo emancipatório", textos bastante esclarecedores estão no livro organizado por Boaventura de Sousa Santos (2003), Reconhecer para libertar: os caminhos do cosmopolitismo multicultural. 
Por fim, é válido tomar a observação de Santos (2002, p. 87) que diz que, por si só, a ocorrência simultânea de fenômenos semelhantes em diferentes países não faz destes um "fenômeno global". Para que possamos caracterizá-los como tais, ele ressalva a necessidade de que "causas endógenas, diferentes de país para país, tenham entre si afinidades estruturais ou partilhem traços de causas remotas, comuns e transnacionais". Se observarmos os diversos fenômenos étnicos ocorridos

\section{Referências}

ABREU, Capistrano de. Capítulos de história colonial. 6 ed. Rio de Janeiro: Civilização Brasileira, 1976.

AGIER, Michel. Distúrbios identitários em tempos de globalização. Revista Mana - Estudos de Antropologia Social, v. 7, n. 2, 2001. p. 7-33.

DARNTON, Robert. O grande massacre de gatos. Rio de Janeiro: Graal, 1986.

FREYRE, Gilberto. Homens, engenharias e rumos sociais. Rio de Janeiro: Ed. Record, 1987.

GORENDER, Jacob. O escravismo colonial. São Paulo: Ática, 1978.

LE GOFF, Jacques. A História Nova. São Paulo: Martins Fontes, 2001.

LEONARDI, Victor. Entre árvores e esquecimentos: história social nos sertões do Brasil. Brasília, DF: Paralelo 15, 1996.

MARTIUS, Karl P. von. Como se deve escrever a história do Brasil. Revista Trimensal de História e Geografia, n. 24, jan. 1845.

MONTEIRO, John. O desafio da história indígena no Brasil. In: SILVA, A. L. da; GRUPIONI, L. D. (Orgs.) A temática indígena na escola: novos subsídios para professores de $1^{\circ}$ e $2^{\circ}$ graus. Brasília: MEC/MA; Rio de Janeiro: Unesco, 1995.

MOREIRA, Vânia Maria Losada. Índios no Brasil: marginalização social e exclusão historiográfica. Diálogos Latinoamericanos, n. 3, 2001.

OLIVEIRA FILHO, João Pacheco de. Uma etnologia dos "índios misturados"? Situação colonial, territorialização e fluxos culturais. Revista Mana, 4(1): 47-78, 1998.

(Org.). A viagem da volta: etnicidade, política e reelaboração cultual no Nordeste indígena. Rio de Janeiro: Contra Capa, 1999.

PESAVENTO, Sandra. História \& História Cultural. Belo Horizonte: Autêntica, 2003.

PORTELA, Cristiane de A. Nem ressurgidos, nem emergentes: em diferentes partes da América e da África, perceberemos que se apresentam traços comuns de afirmação identitária, apesar de contextos históricos específicos, já que têm como pano de fundo uma mesma motivação: as sujeições coloniais a que foram submetidos. O fato de tantos movimentos étnicos terem "despontado" no fim do século XX e no início do XXI indicam que "um terreno propício" foi por eles encontrado... talvez a própria globalização, e não um movimento contrário a esta. a resistência histórica dos Karajá de Buridina em Aruanã, Goiás (1980-2006). Goiânia, 2006. Dissertação (Mestrado em História) - Universidade Federal de Goiás.

PRADO JR., Caio. Formação do Brasil contemporâneo. 15 ed. São Paulo: Brasiliense, 1977.

RIBEIRO, Darcy. Os índios e a civilização. Rio de Janeiro: Vozes, 1970.

ROCHA, Leandro M. A política indigenista no Brasil: 19301967. Goiânia: Ed. UFG, 2003.

SAHLINS, Marshall. Ilhas de história. Rio de Janeiro: Jorge Zahar, 1990.

O pessimismo sentimental e a experiência etnográfica: por que a cultura não é um objeto em via de extinção (parte I). Mana-Estudos de Antropologia Social, v. 3, n. 2, 1997.

SANTOS; ARRISCADO. Para ampliar o cânone do reconhecimento, da diferença e da igualdade. In: SANTOS, Boaventura de Souza (Org.). A globalização e as ciências sociais. São Paulo: Cortez, 2002.

(Org.). Reconhecer para libertar: os caminhos do cosmopolitismo multicultural. Rio de Janeiro: Civilização Brasileira, 2003, v. 3.

SOUZA FILHO, Carlos F. Marés. A universalidade parcial dos direitos humanos. In: GRUPIONI; VIDAL; FISCHMANN. Povos indígenas e tolerância: construindo práticas de respeito e solidariedade. São Paulo: Edusp; Unesco, 2001. TAUNAY, Affonso de. História geral das bandeiras paulistas. São Paulo: 1979.

VAINFAS, Ronaldo. Colonização, miscigenação e questão racial: notas sobre equívocos e tabus da historiografia brasileira. Revista Tempo, v. 8, Rio de Janeiro: UFF, 1999, p. 3-12.

VARNHAGEN, F. A. de. História geral do Brasil [1854]. São Paulo: Melhoramentos, 1978.

VIANA, Oliveira. Populações meridionais do Brasil. São Paulo: Monteiro Lobato \& Comp. Editores, 1920. 


\title{
For a more anthropological history: indigenous peoples in contemporary times
}

\begin{abstract}
In this text, I propose a reflection on indigenous peoples' history by scanning Brazilian historiography in search for historians' perception concerning the historical role played by indigenous peoples in our history. Thus, I present a brief overview of the treatment given to indigenous history since the moment of professionalization of history as a school subject, bringing as a hypothesis the idea that natives have been made socially invisible and discursively silenced. That is to say that, for a long time, their voices were inaudible and their histories, invisible. I consider that the way in which indigenous history has been treated generated a stigmatizing circle of historiographical marginalization, as well as of a social erasing reinforced by this exclusion. In the search for a proposal of a 'more anthropological history', I make use of the readings of João Pacheco de Oliveira Filho, Marshall Sahlins and Boaventura de Sousa Santos, considering new theoretical possibilities for a reading of indigenous societies in contemporary time.

Key words: indigenous people; historiography; historical anthropology; indigenous history.
\end{abstract}

\section{Por una historia más antropológica: los indígenas en la contemporaneidad}

\begin{abstract}
Resumen
Propongo, en este texto, una reflexión sobre la historia indígena, recorriendo algunos momentos de la historiografía brasileña en busca de la percepción de los historiadores sobre el papel histórico desempeñado por los indígenas en nuestra historia. Presento un breve panorama del tratamiento dado a la historia indígena desde el momento de la profesionalización de la disciplina Historia, trayendo como hipótesis la idea de que los indígenas fueron in-visibilizados socialmente y silenciados discursivamente, o sea, durante mucho tiempo sus voces estuvieron inaudibles y sus historias invisibles. Considero que la manera por la cual fue tratada la historia indígena generó un círculo de estigmatización entre la marginalización historiográfica que les fue destinada y el silenciamiento social al que fue forzado como resultado de esta exclusión. En busca de una propuesta de "historia más antropológica", recurro a las lecturas de João Pacheco de Oliveira Filho, Marshall Sahlins y Boaventura de Sousa Santos, considerando nuevas posibilidades teóricas para una lectura de las sociedades indígenas en la contemporaneidad.
\end{abstract}

Palabras clave: indígenas; historiografía; antropología histórica; historia indígena.

Data de recebimento do artigo: 21-01-2008

Data de aprovação do artigo: 24-09-2008 